\title{
OFICINA DE CRIATIVIDADE COM PAIS DE CRIANÇAS DEFICIENTES
}

\author{
Creativity Workshop with the disabled children's parents \\ Talleres de Creatividad con padres de niños portadores de deficiencia
}

Adriana Cristina Pereira

Micheli ManZin Cesarini

Givliana Bilbao

\begin{abstract}
Resumo: Este trabalho teve como ponto de partida a reflexão sobre inclusão social versus preconceito, que ainda vincula deficiência à incapacidade. Pais de crianças portadoras de deficiência, também, sofrem com a discriminação direcionada aos seus filhos, se culpam pelo seu nascimento e se sobrecarregam com responsabilidades físicas e emocionais. Com o objetivo de criar, através da arte, um espaço de ressignificação dos sentimentos dos pais, gerados pelo nascimento do filho deficiente, bem como a possibilidade de apoiá-los na compreensão e reflexão do seu papel junto aos seus filhos, este estudo foi conduzido utilizandose técnicas de Oficina de Criatividade. O presente foi realizado com pais de crianças portadoras de deficiência, usuárias da Associação Campineira de Recuperação da Criança Paralítica.
\end{abstract}

Palavras-chave: Deficiência; Oficina de Criatividade; Pais; Sentimentos.

\begin{abstract}
This work took as its starting point the debate on social inclusion versus prejudice, which also binds disability to inability. Disabled children's parents also suffer from discrimination headed to their children, they blame themselves for its birth and they get covered with physical and emotional responsibilities. Aiming to create, through art, an area of ressignification of the parents' feelings, due to the birth of that disabled child, and also the possibility of assisting them in understanding and reflection of their role with their children, this study was conducted using up Creativity Workshop techniques. This was conducted with the disabled children's parents, users of the Campineira Recovery Association of Paralytic Child.
\end{abstract}

Keywords: Disability; Creativity Workshop; Parents; Feelings.

Resumen: Este trabajo tuvo como punto de partida la reflexión acerca de la inclusión social versus prejuicios, que además vincula la deficiencia a la discapacidad. Padres de niños portadores de deficiencia, también sufren con la discriminación hacia sus hijos, se culpan a sí mismos por el nacimiento de éstos y se sobrecargan con responsabilidades físicas y emocionales. Con el objetivo de crear, por medio del arte, un espacio de gran relevancia a los sentimientos de los padres, generados con el nacimiento de un hijo deficiente, así como, la posibilidad de apoyarlos en la comprensión y reflexión de su papel junto a su hijo, este estudio fue conducido utilizando técnicas de Talleres de Creatividad. El mismo fue realizado con padres de niños portadores de deficiencia, usuarios de la Asociación Campinera de Recuperación del Niño Paralítico.

Palabras-clave: Deficiencia; Taller de Creatividad; Padres; Sentimientos.

\section{Introdução}

Este trabalho é fruto do estudo realizado para o cumprimento de estágio supervisionado da disciplina de Oficina de Criatividade do curso de Psicologia da Universidade Paulista da cidade de Campinas, realizado com cuidadores de crianças portadoras de deficiência, usuárias dos serviços da Associação Campineira de Recuperação da Criança Paralítica.

A instituição consentiu com a realização do trabalho com os pais das crianças usuárias da mesma, de acordo com o Termo de Consentimento Institucional, assinado por ela.

A instituição, também conhecida como Casa da Criança Paralítica de Campinas, iniciou suas atividades em 1954, com o intuito de recuperar as vítimas da paralisia infantil. Com a erradicação da poliomielite, crianças com outros problemas de saúde, como mielomenigocele, lesão cerebral, traumas, acidentes, etc, são atendidas pela instituição. Contudo, a missão de integrar e reintegrar os portadores de necessidade especial no meio social não mudou, tampouco, a idéia de recuperar e dar aos usuários melhores condições de vida, proporcionando, assim, todos os cuidados necessários às crianças com o objetivo de habilitar, reabilitar e reintegrá-las à sociedade, porém a instituição não consegue atender à demanda dos pais, os quais, também, sofrem com o preconceito e culpa pela geração de um filho deficiente. Dessa forma, tal população, carente de cuidados, atraiu os olhares das pesquisadoras que desenvolveram um trabalho através das técnicas de oficina de criatividade, com o objetivo de criar um espaço de arte e criação para que os cuidadores tivessem a oportunidade de expressar e refletir sobre os sentimentos gerados a partir do nascimento do filho defi- 
ciente, bem como a possibilidade de encontrar apoio para compreender seu papel junto a seus filhos.

Segundo Amiralian (1986), o aspecto físico, a força e a beleza foram e ainda são características valorizadas pelo homem. A evolução das ciências humanas e da psicologia trouxe uma nova visão a respeito dos excepcionais, colocando a excepcionalidade como um fenômeno social, no sentido de que esta só pode ser entendida no contexto maior das dinâmicas interpessoais, em ações ambientais suscitadas pela presença e atuação do individuo divergente, refletindo sobre a autoimagem e autoestima para o individuo excepcional e os comportamentos desses indivíduos começaram a ser estudados e, consequentemente, surgiram programas e técnicas capazes de promover o seu desenvolvimento. A partir disso, a excepcionalidade deixou de ser considerada uma "doença" e passou a ser considerada uma "condição", que determinados indivíduos se encontram e para qual são necessárias medidas educacionais, sociais, psicológicas e médicas específicas, com o intuito de favorecer o desenvolvimento e o ajustamento social.

A mesma autora considera que, o fenômeno da excepcionalidade não reside somente em um indivíduo, mas sim, ocorre numa família. O indivíduo excepcional só pode ser compreendido quando a dinâmica das relações interpessoais é analisada, bem como, os conceitos e valores da sociedade em que está inserido. A família é muito importante não só para o indivíduo portador de necessidades especiais, pois é a unidade social básica para o estabelecimento dos relacionamentos interpessoais e estes se constituirão como modelo. É na interação familiar que o indivíduo se desenvolve e vai configurando sua personalidade e a partir disso se determinam as características sociais, éticas e morais da comunidade adulta. A presença de uma criança deficiente poderá trazer conflitos e impacto nos aspectos de recompensa e gratificação esperados pelos pais, já que vêem os filhos como extensões de si mesmos.

Como explicitado abaixo, alguns fatores podem influenciar nas atitudes de aceitação da doença do filho e na vida desses pais e da família. O sentimento de culpa pode ser um deles, como é apontado por Amiralian (1986), o diagnóstico de um filho deficiente pode gerar um sentimento de frustração nos pais, buscando entender porque isso aconteceu com eles, mas na maioria das vezes a excepcionalidade não tem uma resposta e então os pais saem em busca desta no passado, gerando sentimentos de ansiedade e culpa, com a suposição de que a deficiência da criança é uma conseqüência de atos omitidos ou praticados com fantasias freqüentemente relacionadas à gravidez.

Assim, é preciso encontrar um culpado pelo o ocorrido e na maioria das vezes os pais se sentem assim. De acordo com Miller (1995), "Sentir-se responsável pelo problema de seu filho é uma forma de tentar elaborar o que deu de errado. Assume-se a culpa, porque quando existe um culpado, ao menos existe uma explicação" (p. 55).
Amiralian (1986) diz que, diante desses sentimentos, os pais se utilizam de mecanismos de defesa que buscam a redução da ansiedade e a solução de conflitos, e suas atitudes assumem características que ao invés de facilitar o desenvolvimento da criança tornam-se um obstáculo a mais para ela, como a negação da doença colocando a criança em situações de tensões e frustrações desnecessárias, a superproteção quando os pais ao invés de ajudar a criança a realizar determinada tarefa, realizam-na para ela, bem como a projeção quando os pais colocam nos profissionais a responsabilidade dos cuidados e falta de desempenho satisfatório de seu filho.

Mas, ainda segundo a autora, atitudes positivas também ocorrem nessas situações e os pais conseguem ajustar-se satisfatoriamente à situação frustradora e assumem a atitude de aceitação, que é mais sadia e desejada tanto para a criança como para a relação familiar. Essa aceitação não deve ser confundida com passividade, mas sim como conhecimento real e objetivo das limitações e possibilidades da criança, buscando os recursos e ajuda necessários para ela.

Para auxiliar no processo de aceitação e adaptação do filho doente e da família, Monteiro, Matos e Coelho (2002) dizem que é necessário que a mãe expresse e elabore sentimentos para conseguir assumir o seu filho com a sua deficiência e que por isso o processo de adaptação psicológica da mãe ao seu filho com paralisia cerebral, é muito complexo, uma vez que experienciam níveis de estresse mais elevados do que mães de crianças saudáveis, pois o excesso de cuidados exigidos pela criança com paralisia cerebral, traz como conseqüência a diminuição de seus tempos livres, alteração na situação profissional, sobrecarga financeira elevada, além dos sentimentos de culpa e sensação de isolamento.

Antes de tudo, os pais são pessoas. Ter um filho é apenas uma parte do complicado papel desempenhado por um indivíduo. Eles também são filhos ou filhas, maridos ou esposas, trabalhadores, cidadãos, que recebem um novo papel, tornando-se, por extensão, "pais especiais", uma vez que o nascimento de uma criança deficiente fará com que os pais enfrentem o desafio de tentar compreender sentimentos e atitudes oriundas dessa condição (Buscaglia, 1997).

O autor ainda aponta que existe uma conscientização por parte dos profissionais do fato de que mesmo os melhores programas educacionais e terapêuticos oferecerão poucos benefícios à criança excepcional, se não existir o apoio por parte dos pais, pois, segundo, estudo realizado com três grupos de crianças em fase pré-escolar, expostos a diferentes tipos de experiência, onde todos freqüentavam o jardim da infância comum, o segundo e o terceiro grupos participavam também de um programa de intervenção que enfatizava áreas cognitivas discutidas por Piaget e no terceiro grupo os pais freqüentavam a terapia oferecida a estes, indicou que o fator que proporciona as mais altas performances das crianças nos testes cogniti- 
vos e também um ambiente mais estimulante em casa é o programa de terapia dos pais.

Milman (1970, citado por Buscaglia, 1997) descreveu outro estudo, onde pais de crianças com pequenas disfunções cerebrais participavam semanalmente de encontros abertos, com sessões de sessenta a noventa minutos, pelo período que desejassem, com propósito de fornecer informações a respeito de disfunções cerebrais e de como essas deficiências afetam a vida da criança, assim como dar oportunidade aos pais de discutirem suas próprias atitudes e seus sentimentos em relação aos filhos. Assim, foi observado que, pela primeira vez, os pais passaram a relatar maior compreensão da disfunção cerebral, assim como uma maior eficácia em tratar o comportamento dos filhos. Yura, Zuckerman, Betz e Newman (1979, citado por Buscaglia, 1997), em projeto de desenvolvimento dos pais, observaram que estes apresentavam uma atitude mais positiva em relação à capacidade de seus filhos e o comportamento indisciplinado das crianças decrescia com freqüência após os pais terem participado do projeto.

Quanto à terapia de pais de deficientes, Buscaglia (1997) atribui ao terapeuta o papel de ajudá-los a lidarem com os sentimentos negativos em relação à deficiência e de oferecer-lhes apoio psicológico e moral, e Kronich (1978, citado por Buscaglia, 1997) descreve o grupo como um fórum no qual os pais podem expressar, com segurança, a raiva e o desapontamento, assim como ouvir o que os outros pais sentem.

Apolônio, Castilho, Alava e Caixa (2000) apontam que a criança não pode ser encarada como um ser isolado do seu meio envolvente. Está integrada na família e na sociedade e qualquer intervenção que vise o seu desenvolvimento deve envolver ativamente os pais, o que facilita tomada de consciência das suas próprias competências e capacidades e ajudando-os a lidar com a deficiência ou limitação do filho. $\mathrm{O}$ apoio a prestar à família deve também procurar prevenir que os irmãos sejam tratados de forma diferente, podendo gerar sentimento de exclusão, o que pode também ser estendido à família mais alargada que pode funcionar como um suporte importante em todo o processo.

As autoras destacam ainda que atualmente, no Centro de Desenvolvimento e Intervenção Precoce do Núcleo de Évora da Associação Portuguesa de Paralisia Cerebral, através do trabalho de intervenção precoce, toda a intervenção com a criança tem lugar no contexto de um modelo centrado na família, muito mais abrangente, que foca a sua atuação na família como um todo, o que implica na adoção de uma perspectiva mais global ou ecológica do desenvolvimento, que não diferencie abordagens e intervenções separadas com os pais e as crianças. Os pais devem ser considerados elementos fundamentais e capazes de intervir de forma positiva no desenvolvimento do seu filho, recebendo para isso o apoio necessário das redes sociais, formais e informais, existentes na comunidade.
A partir das referências citadas, os cuidados que pais de crianças portadoras de deficiência devem receber fica evidente, assim o espaço de expressão, reflexão e ressignificação dos sentimentos proporcionados pelo criar através das oficinas de criatividade poderá contribuir para que ocorra uma melhora na vida dessas pessoas.

O tema oficina de criatividade nos remete ao ato de criar e ser criativo, e que pode ser entendido por uma expressão resultante da liberdade do indivíduo que se depara com o exercício, com uma atitude laboral. Segundo Cupertino (2001), é necessário que exista uma disponibilidade interna para a criação ou algum recurso pessoal a ser desenvolvido para que a oficina aconteça, já que a idéia de ser criativo é requisito fundamental para a manutenção da saúde mental numa época de constantes mudanças e que afeta, diretamente, as relações humanas.

Conforme May (1982), ser criativo requer certa dose de coragem e exige que o indivíduo se coloque como veículo de novas visões do mundo, mostrando que a condição básica de ser criativo é a liberdade. "A coragem criativa é a descoberta de novas formas, novos símbolos, novos padrões segundo os quais uma sociedade pode ser construída". (p. 19)

Ainda segundo May (1982), a arte nos faz sentir mais profundamente a importância do ser humano. Nem sempre a expressão é feliz, mas cada um de nós guarda no íntimo certas formas básicas, em parte genéricas, em parte experimentais na sua origem, que são os objetos expressos pelos artistas. Assim muito do que não é expresso comportamental ou verbalmente pela pessoa, pode ser observado na arte.

Nesse sentido, é possível pensar num homem repleto de expectativas e que através do ato de criar e da produção possa perceber a possibilidade de desenvolvimento e construção de si mesmo e ter a oportunidade de rever os significados que dá às coisas, às pessoas, à vida. Como diz Pompéia e Sapienza (2004)

...o homem é movido por aquilo que ainda não é. O que ainda não é é expectativa, projeto, imagem, sonho; mesmo que nunca venha a ser, que permaneça como pura possibilidade, esse ainda não é é exatamente o que permite a possibilidade de ser. (p. 18).

A obra de arte é uma coisa que fala ao homem, mesmo nas que não estão presente a fala. Criar é a composição de uma obra, cuja fala é a própria fala do autor. " $O$ artista diz alguma coisa ao fazer sua obra", mas a palavra criar também pode ter o sentido de que "o artista cria, não porque quer dizer alguma coisa, mas porque ele escuta alguma coisa que lhe fala". (p. 22)

As oficinas de criatividade possibilitam a representação e expressão da arte, que é visto como material simbólico para explorar os materiais e conteúdos psíquicos dos participantes. Elas, as oficinas, podem ser caracterizadas como espaços de elaboração da experiência pessoal 
e coletiva através do uso de recursos expressivos como movimento corporal, expressão plástica e de linguagem. Estes processos criativos resultam na produção de objetos tais como desenhos, pinturas, esculturas entre outros (Schmidt \& Ostronoff, 1999).

Ainda segundo as autoras, a realização das oficinas deve acontecer em grupos, uma vez que os objetivos destas, também dependem da espontaneidade de participação e envolvimento das pessoas do grupo. É interessante que a aplicação de uma oficina de criatividade aconteça num ambiente amplo, ventilado e confortável por um período de, aproximadamente, duas horas para que se tenham condições necessárias e suficientes para a promoção de um tempo e um espaço que sirvam como referência e suporte para o trabalho de criação, apesar destes não serem os principais requisitos, pois, deve-se levar em conta a oficina a ser realizada, a partir da qual o oficineiro estabelece o mais adequado para sua realização. Sua estrutura pode ser dividida em três etapas: aquecimento, realização do trabalho e fechamento, onde o papel do facilitador é muito importante. Este deve ainda definir alguns pontos, tais como a população alvo, local, horário, temática a ser utilizada, estratégia de divulgação, organização e inscrições, para que assim o grupo possa se formar. É necessário que, nos primeiros encontros, o facilitador da oficina reserve um espaço para ouvir os participantes sobre suas expectativas e motivações, o que proporciona a criação de laços afetivos, bem como, a possibilidade de avaliar a temática das oficinas.

Segundo Jordão (1999), as oficinas de criatividade proporcionam, através dos materiais de possibilidade criativa, o reavivar do indivíduo e o seu sentido existencial, elas podem devolver ao indivíduo o caráter de inserção, de produção e de sonho. É no ato consciente e no re-experimentar os sentidos, que as pessoas se propõem no desejo de se inserirem na vida, de retomarem seus caminhos, é fazendo e aprendendo que a pessoa se torna pertinente a um grupo. Durante as oficinas os participantes se surpreendem criativos através de seus produtos, gestos ou pela fala. Ao participante da oficina é dada a oportunidade de compartilhar e reconhecer seus conteúdos simbólicos através de sua experiência produtiva, “...toma consciência de sua história, narra e expõe para os demais...” (Jordão, 1999, p. 332). O clima acolhedor garante um espaço para que o participante da oficina se coloque verbalmente ou não, cuidando assim para que o processo garanta um desenvolvimento pessoal e social, bem como, a criação de uma atmosfera de aprendizado, criação, produção e autoconhecimento, tornando assim, as oficinas uma prática de caráter terapêutico.

Para as autoras Schmidt e Ostronoff (1999), alguns materiais e recursos têm sido utilizados para a aplicação das oficinas de criatividade, tais como os Recursos Corporais (atividades que possibilitam a ampliação e contato com o corpo trazendo sensações de relaxamento, prazer, tensão, mas, sobretudo, trazendo um sentimento de consistên- cia); Estimulação Sensorial (possibilita o conhecimento do mundo através dos órgãos do sentido); Música (facilita o relaxamento e favorece a diminuição da ansiedade) e os Recursos Plásticos (possibilita concretização da experiência pessoal).

Contudo, o que interessa é que a "obra" oriunda das oficinas possa ser a expressão de cada um, onde seja possível a reflexão e autoconhecimento. A possibilidade de formular conceitos sobre si mesmo surge na condição do encontro com o outro, a possibilidade de transformação, de autoquestionamento, de criação de novos sentidos para a identidade: “... o encontro com aquilo que não sou é que permite a percepção do que sou. Essa reflexão só se torna possível no contato com a diferença" (Kemp, 2005, p. 33)

O pressuposto de que existe uma disponibilidade interna para a criação, ou algum recurso que possa vir a ser desenvolvido, a necessidade de ser criativo, para auxiliar na adaptação e manutenção da saúde mental, devido às mudanças que vivemos hoje em nossa sociedade acelerada, torna essencial a prática das oficinas terapêuticas, pois durante sua aplicação é o momento que se tem para parar e refletir, se ver, se sentir, um momento seu. $\mathrm{O}$ ato de criar deveria estar presente no dia-a-dia das pessoas para promover saúde mental, autoavaliação e, consequentemente, melhora da autoestima.

A importância desse processo de convivência social e trabalho em grupo é explicada por Rogers (1977, citado por Schmidt \& Ostronoff, 1999, p. 343), "A tessitura destes laços e de comunicação guarda uma relação estreita com a possibilidade de elaborar e transmitir experiência através de produções que transcorrem no eixo de uma aprendizagem afetivo-intelectual, no eixo da aprendizagem significativa".

\section{Objetivos}

O desejo de atender à demanda da Casa da Criança Paralítica de Campinas, proporcionando um olhar de cuidado aos pais das crianças usuárias da instituição, oferecendo as Oficinas de Criatividade a esses pais, para que possam utilizar esse momento como um cuidado a eles e não somente aos filhos, nos pareceu bastante importante, pois como refere Babcock e Keepers (1977):

Qualquer que seja o status das figuras parentais, as crianças continuam tendo que enfrentar as tarefas psicológicas de cada estágio de desenvolvimento. Da mesma forma, os próprios pais têm que satisfazer suas necessidades de desenvolvimento, qualquer que seja sua organização de vida (p. 21).

A aplicação das oficinas de criatividade com abordagem terapêutica, com os pais das crianças atendidas pela instituição tem, em partes, o mesmo objetivo do trabalho 
da instituição com as crianças, que é o de buscar proporcionar melhor qualidade de vida, convívio social, aumento de autonomia, para as crianças deficientes, e as oficinas, para os pais e/ou cuidadores. Pensando nisso, a aplicação das oficinas de criatividade foi direcionada àqueles que cuidam das crianças deficientes e que, até então, não possuíam nenhuma ocupação e permaneciam ociosos na sala de recepção da instituição enquanto aguardavam o término do tratamento de seus filhos.

Os pais que participaram das oficinas de criatividade, na maioria, possuem dificuldades financeiras e alguns apresentam recursos psíquicos reduzidos, com baixa capacidade de abstração e processo de elaboração de pensamento, porém, foram capazes de participar das atividades. Exceto um participante, pai de uma das crianças, as demais eram do sexo feminino, sendo 9 mães, 2 tias, 1 avó e uma cuidadora das crianças usuárias da instituição

\section{Metodologia}

Foram realizados nove encontros com os participantes das oficinas na Casa da Criança Paralítica de Campinas, sendo que foram aplicadas oito oficinas de criatividade, uma em cada encontro, e um encontro de encerramento. Os encontros foram semanais com o foco de expressão de sentimentos dos participantes através da arte, com duração aproximada de 90 minutos cada. Os encontros aconteceram nas instalações da própria instituição numa sala ampla e de boa iluminação. As atividades foram facilitadas pelas "oficineiras" e baseadas no uso de recursos expressivos de natureza artística, bem como, devidamente supervisionadas pela professora da disciplina.

Os encontros eram realizados com um grupo de pais e/ou cuidadores, sem frequência constante, já que o grupo era formado pelos pais que estavam aguardando seus filhos na sala de espera. Foram planejadas atividades usando recursos expressivos variados, como colagem, desenho, pintura e expressão verbal, de acordo com o funcionamento do grupo, exceto pela primeira oficina, que serviu para propiciar o conhecimento dos participantes do grupo, que utilizando-se de cartolina branca, revista, tesoura e cola, tinham como objetivo fazer um "Anúncio" de si mesmo, para que as oficineiras pudessem conhecer um pouco dos participantes, assim como eles pusessem se conhecer e também que pudessem refletir sobre quem são para expor na cartolina.

No segundo encontro, foi solicitado aos participantes da oficina que fizessem o "Gráfico de suas Vidas", utilizando-se de cartolina branca, lápis de cor e giz de cera, com o objetivo de auxiliar os participantes a pensar sobre suas vidas, refletir sobre fatos ocorridos, a fim de experiênciá-los de forma diferente, podendo estes ter novo sentido com a vivência da oficina. O conteúdo dos desenhos dos participantes que eram pais de crianças portadoras de deficiência foi semelhante e expressou, basicamente, o mesmo sentimento, a difícil tarefa de cuidar de um filho deficiente.

Na aplicação da oficina da "Folha em Branco", as oficineiras solicitaram aos participantes que, utilizando-se de cartolina branca, tinta guache e pincel, expressassem coisas boas da vida, o que mais gostavam e que lembravam com alegria, com o objetivo de auxiliá-los a relembrar aspectos bons de suas vidas, tendo um momento para pensar em si mesmos através de lembranças, situações ou momentos que lhe trouxeram alegria, buscando um olhar para si e não somente para o filho como vinham apresentando. Nesse encontro, observou-se que os participantes puderam falar de si através da criação e trocar experiências com o grupo, apesar de expressarem certo desconforto para iniciar a tarefa, já que não sabiam o que desenhar e como seria a qualidade dessa criação.

Para a realização da quarta oficina, "Caixa Espelho", foram utilizadas caixas de sapato embrulhadas com papel de presente e um espelho colado no fundo de cada uma. Cada um dos participantes deveria escolher uma das caixas dispostas sobre a mesa e, em seguida, tentar adivinhar o conteúdo da caixa, com a dica de que era algo "muito importante". Em seguida, foi solicitado que abrissem a caixa, a fim de que descobrissem nela um espelho, o qual refletia sua própria imagem, que também pode ser considerada importante. A oficina teve como objetivo que os participantes pensassem e verbalizassem o que consideravam importante, que poderia estar dentro da caixa e porque consideravam isso importante e em seguida que pudessem refletir sobre estarem na posição de pessoas especiais, que também cabem na caixa, buscando um olhar para si mesmos e não apenas para os filhos. Durante seus relatos, os participantes não tiveram a percepção de se colocarem dentro da caixa, mas quando revelado o conteúdo, todos ficaram surpresos conseguindo verem-se como importantes.

No quinto encontro, mais uma vez, os participantes deveriam se expressar através de um estímulo oferecido pelas oficineiras. Para isso, foram utilizados diversos e variados tipos de objetos, que foram dispostos sobre uma mesa e os participantes receberam, no primeiro momento, a instrução de que deveriam escolher e pegar apenas um deles e, num segundo momento, que deveriam escolher e pegar mais um objeto, mas, desta vez, deveriam escolher um objeto com o qual não se identificassem. A oficina teve como objetivo que os participantes expressassem verbalmente porque escolheram determinado objeto, bem como, lembranças e sentimentos que estes pudessem desencadear, refletindo e compartilhando suas experiências com os demais participantes do grupo. Nessa oficina, "Objetos Significativos", os participantes puderam interagir com os demais membros do grupo e perceber que outros também tiveram ou vivenciaram histórias semelhantes, principalmente, quando recordaram as dificuldades na infância. 
Para a realização da oficina do sexto encontro, foram utilizadas diversas palavras, impressas em pequenos pedaços de papéis, colados com fita adesiva em balas e colocadas em um recipiente sem tampa. O recipiente com as balas foi colocado no centro da mesa, e os participantes, sentados ao redor da mesa, pegavam aleatoriamente uma bala, lia em voz audível qual a "Palavra Sorteada" e, em seguida, falava o que aquela palavra representava ou lembrava para eles. O objetivo era que os participantes expressassem verbalmente, o que sentiam quando liam e pensavam sobre aquela palavra, refletindo sobre o verdadeiro significado que esta possuía em sua vida, compartilhando e trocando experiências com os demais participantes do grupo, o que é muito importante pensando num momento de integração, já que se trata de pais que, a princípio, sofrem de questões semelhantes, mas que raramente se permitem "estar em grupo", tampouco, compartilhar suas experiências.

A sétima oficina, "Qualidades e Machucados”, aconteceu em três etapas. Na primeira os participantes deveriam fazer um desenho de si mesmos utilizando uma cartolina branca, cortada ao meio, lápis de cor ou giz de cera. Na segunda, os participantes da oficina foram instruídos a colar uma estrela em cada local onde acreditavam ter algo bom ou positivo em si mesmo, e um curativo onde existisse um machucado. Na terceira etapa foi solicitado aos participantes que falassem ao grupo o que significava cada estrela e cada curativo, com o objetivo de reflexão e capacidade de identificação dos participantes acerca das qualidades e aspectos positivos em si mesmos, assim como suas dores e sentimentos negativos, os "machucados". Os participantes demonstraram certa resistência no momento do desenho da auto-imagem, porém, durante a colagem das estrelas e curativos, participaram normalmente, sentindo-se encorajados a expressarem seus sentimentos a respeito de suas qualidades e machucados ao passo que viam o outro participante colar seus adesivos.

A última oficina foi considera uma das mais significativas, na qual se aplicou a oficina de "Mosaico". Para a realização dessa atividade, foram utilizadas cartolinas brancas, cola e pequenos pedaços de cartolinas coloridas cortadas em formas aleatórias, a fim de formar um mosaico. Aos participantes foi dada a instrução que, de maneira livre, construíssem o que tivessem vontade, já que o objetivo era criar um espaço onde, a partir de um tema livre e de uso de um material colorido e sem forma definida, diferente dos que haviam utilizado anteriormente, pudessem ter seus sentidos estimulados. Diferentemente dos encontros anteriores, os participantes permaneceram em silêncio enquanto produziam os trabalhos. Ao final, quando todos haviam verbalmente expressado acerca de suas criações, percebeu-se que, em comum, possuem o sonho de ter sua própria casa e que através da criação recordaram de fatos marcantes da época de infância, referindo-se apenas a respeito de si próprios e não da doença dos filhos.
No encontro de "Encerramento" as oficineiras relembraram, juntamente com os participantes, todas as oficinas realizadas durantes os encontros, com o objetivo de finalizar as oficinas e levantar dados a respeito de como os participantes se sentiram ao realizar as tarefas propostas e qual impacto tais atividades puderam ter causado em cada um deles. A partir da fala dos participantes, constatou-se a satisfação de todos por terem participado das atividades, tanto com relação ao simples fato de "fazer algo" como com relação ao benefício que puderam vivenciar a partir da expressão de seus sentimentos. Relataram a importância do conhecimento que puderam ter de si próprios e trocar experiências com os demais cuidadores, já que, há algum tempo, freqüentavam a mesma instituição, mas poucos se conheciam.

\section{Discussão}

Vários temas e mudanças de comportamentos puderam ser observados nas pessoas que participaram das oficinas durante o período que estas foram proporcionadas aos pais das crianças atendidas pela Casa da Criança Paralítica de Campinas. Um dos pontos que pôde ser observado ao longo de todos os encontros de oficina, desde o primeiro, foi a possibilidade dos participantes se conhecerem, como na aproximação ocorrida entre eles, com o decorrer dos encontros, observada pelas oficineiras, funcionários da instituição e por eles mesmos. Construindo um espaço de convivência no qual passa a ter sentido e importância a experiência de cada um, como aponta Schmidt e Ostronoff (1999) as oficinas suscitam o rompimento com estados de isolamento, ativam laços sociais e de comunicação, contribuindo para o desencadear de sentimentos de enraizamento e de pertença social.

Durante as atividades percebeu-se que para alguns pais, falar do passado, ou seja, reviver algumas situações e pensar em suas possibilidades foi doloroso. Foi possível perceber durante as três primeiras oficinas que, o fato de se considerarem "pais especiais" trouxe certo "impedimento" para as reflexões dos trabalhos, já que possuem dificuldade para se perceberem como pessoas, independentes de pais de crianças deficientes.

No final da aplicação da quarta oficina (Caixa Espelho), foi possível perceber certa movimentação no sentido de uma possibilidade de se perceberem como indivíduos e que poderiam usufruir o "momento das oficinas" para pensar em si mesmo. Porém, no início da aplicação, os participantes não foram capazes de ver o reflexo de seus rostos no espelho devido a enorme dificuldade de se considerarem "importantes", não se reconhecerem como uma pessoa independente da existência do filho, incapazes de ter momentos felizes sem a presença destes, não reconhecer o recebimento de carinho ou momentos de diversão na vida, foram motivos importantes para entender que as oficinas puderam causar grande impacto nos participantes. 
A partir da quinta oficina (Objetos Significativos), os participantes foram capazes de deixar de lado, pelo menos durante o período de aplicação das oficinas, a preocupação que têm com os filhos e aproveitar o momento da oficina de criatividade. Assim, puderam, além de recordar de suas épocas de infância, deixar o aspecto concreto de lado e pensar de maneira mais subjetiva. Na sétima oficina (Qualidades de Machucados), se depararam com o desenho de sua auto-imagem e foram capazes de identificar aspectos positivos e negativos em si mesmo.

Duas oficinas parecem ter causado grande movimentação psicológica nos participantes, que foram o "Objeto Significativo", quando todos puderam falar sobre seus sentimentos a respeito do que o objeto os remetia, com lembranças do passado e grande troca de experiências pessoais, causando aparente empatia entre os membros do grupo, assim como a oficina de "Mosaico", com a proposta de uma produção livre, proporcionando grande manifestação de sentimentos e recordação de fatos marcantes da infância.

Essas oficinas proporcionaram, também, a concretização do objetivo das oficineiras em levar a Oficina de Criatividade a essa população, e que só foi possível através da criação de um espaço onde pudessem estimular a expressão e reflexão de seus sentimentos, gerar um momento em que os participantes pudessem pensar em si mesmos e não apenas em seus filhos e deficiência, ao contrário de como vinham se apresentando nas oficinas anteriores, pois apesar do tema ter aparecido na fala de alguns participantes, foi de uma forma "secundária", pois o que predominou foi a experiência de vida pessoal de cada um.

A preocupação inicial dos participantes de não saberem realizar a tarefa proposta de forma adequada e que ficasse com um aspecto bonito, aos poucos foi deixada de lado no decorrer dos encontros, dando lugar a um momento de diversão quando acreditavam que o trabalho não tinha ficado tão bom e se preocupando mais com os sentimentos expressos e trabalhados do que com sua beleza. Aconteceram momentos de respeito e apoio diante do que era compartilhado, como a descoberta de fragilidades que possuem em comum.

A partir do resultado obtido com esse trabalho podemos dizer que ainda há muito a ser desenvolvido e trabalhado com essa população que necessita de cuidados e olhares também para si e não apenas para os filhos, mas que a porta já foi aberta, causando um impacto positivo na vida dessas pessoas, que tiveram a oportunidade de serem cuidadas, sendo possível observar no encontro de encerramento, que os participantes puderam expressar o que cada uma das oficinas lhes fez pensar e refletir acerca de seus sentimentos e experiências de vida, bem como a mudança de interação social entre si.

Foi possível pensar num homem repleto de expectativas e que através do ato de criar e da produção pôde perceber a possibilidade de desenvolvimento e constru- ção de si mesmo e ter a oportunidade de rever os significados que dá às coisas, às pessoas, à vida (Pompéia \& Sapienza, 2004).

\section{Conclusão}

Foi possível observar que, o espaço de expressão, reflexão e ressignificação dos sentimentos proporcionados pelo criar através das oficinas de criatividade, pôde contribuir para que ocorresse uma melhora na vida dessas pessoas e que apesar da resistência de alguns pais em participarem das oficinas, foi enriquecedor a experiência com os que se dispuseram à essa atividade.

Durante os encontros puderam ser trabalhados aspectos acerca dos sentimentos de terem gerado um filho com deficiência e que apesar das verbalizações de conformidade com o fato, dizendo se tratar de crianças especiais que foram "colocadas em suas vidas por Deus", também foi possível perceber a dificuldade de aceitação do fato. Aos poucos, os pais que, até então, não se percebiam como indivíduos separados de seus filhos, puderam iniciar um processo de autoconhecimento e se permitiram estar em contato consigo mesmos.

Proporcionar um olhar de cuidado e atenção à essas pessoas, foi válido e importante, sendo confirmado pelos próprios participantes que expressaram essa necessidade. Dessa forma, a oficina de criatividade mostrou possibilidades de relação entre o oficineiro e os participantes no exercício da profissão de psicólogo, no sentido de promover a inserção dos cuidadores numa rede de troca, onde a figura do psicólogo pôde ser também incluída e os significados das experiências puderam ser compartilhados. Ao propiciar o suporte para que os pais pudessem se autoconhecer e pensar acerca de suas possibilidades, a oficina cumpriu a função de devolver ao indivíduo o caráter de inserção.Assim podemos concluir que o espaço de expressão e reflexão de sentimentos proporcionado pelas oficineiras pôde causar grande impacto na vida dessas pessoas, causando-lhes mudanças positivas, e nesse sentido acreditamos ser importante que novos trabalhos sejam realizados com essa população, a fim de proporcionar-lhes maiores cuidados e abranger um maior número de pessoas.

\section{Referências}

Amiralian, M. L. T. M. (1986). Psicologia do Excepcional. São Paulo: EPU.

Apolônio, A. M., Castilho, C., Alava, L. \& Caixa, R. (2000). A Intervenção Precoce no desenvolvimento de crianças com paralisia cerebral. [Resumo] Em C. Machado (Org.), Interfaces da Psicologia - Volume I. Congresso Internacional "Interfaces da Psicologia". Évora: Departamento de Pedagogia e Educação da Universidade de Évora. Disponível em <http://scholar.google.com.br/scholar?q=\%22A+Interv 
en\%C3\%A7\%C3\%A3o+Precoce+no+desenvolvimento+d e+crian\%C3\%A7as+com + paralisia +cerebral\%22\&hl=pt$\mathrm{BR} \& \mathrm{lr}=\& b \operatorname{tnG}=$ Pesquisar\&lr $>$.

Babcock, D. E., \& Keepers, T. D. (1977). Pais Ok, filhos Ok. Rio de Janeiro: Arte Nova.

Buscaglia, L. F. (1997). Os deficientes e seus pais. Rio de Janeiro: Record/Nova Era.

Cupertino, C. M. B. (2001). A proposta pragmática. Em C. M. B. Cupertino, Criação e formação: fenomenologia de uma oficina (p. 93-100). São Paulo: Arte \& Ciência.

Jordão, M. P. (1999). Oficinas em aconselhamento: um processo em andamento. Em H. T. P. Morato (Org.), Aconselhamento psicológico centrado na pessoa: novos desafios. (p. 331-334). São Paulo: Casa do psicólogo.

Kemp, K. (2005). Corpo modificado, corpo livre? São Paulo: Paulus.

May, R. (1982). A coragem de criar. Rio de Janeiro: Nova Fronteira.

Miller, N. B. (1995). Ninguém é Perfeito: Vivendo e crescendo com crianças que têm necessidades especiais. São Paulo: Papirus.

Monteiro, M., Matos, A.P., \& Coelho, R. (2002). A adaptação psicológica de mães cujos filhos apresentam paralisia cerebral: Revisão da literatura. Revista Portuguesa de Psicossomática [online], 4, 2, 149-178. Disponível em <http://redalyc.uaemex.mx/re_dalyc/pdf/287/28740211.pdf>.

Pompéia, J. A., \& Sapienza, B. T. (2004). Na presença do sentido: Uma aproximação fenomenológica a questões existenciais básicas. São Paulo: EDUC/ Paulus.

Schmidt, M. L. S., \& Ostronoff, V. H. (1999). Oficinas de criatividade: elementos para explicitação de propostas teóricopráticas. Em Henriette T. P. Morato (Org.), Aconselhamento Psicológico Centrado na Pessoa: Novos Desafios (p. 335-344). São Paulo: Casa do Psicólogo.

Adriana Cristina Pereira - Psicóloga graduada pela Universidade Paulista (UNIP-Campinas). E-mail: adrianac_pereira@yahoo.com.br

Micheli Manzin Cesarini - Psicóloga graduada pela Universidade Paulista (UNIP-Campinas). E-mail: micheli_cesarini@yahoo.com.br

Giuliana Bilbao - Doutora em Psicologia pela Pontifícia Universidade Católica de Campinas (PUC-Campinas) e Supervisora de estágio em Oficinas de Criatividade na Universidade Paulista (UNIPCampinas). Endereço Institucional: Universidade Paulista. Av Comendador Enzo Ferrari (Swift). CEP: 13.070-033 - Campinas/SP. E-mail: lgglima@uol.com.br

Recebido em 02.06.09

Primeira Decisão Editorial em 10.10.09

Aceito em 21.11.09 